Recibido: 28-octubre-2013

Aceptado: 14-noviembre-2013

\title{
LAS BASES COGNITIVAS, FISIOLÓGICAS Y NEUROBIOLÓGICAS DE LA EDUCACIÓN
}

LEONARDO WILD

Investigador Educación No Directiva 


\section{RESUMEN}

La educación formal ha sido, a lo largo de la historia, una herramienta para mantener la desigualdad y lograr el control social, ya sea por falta de acceso al conocimiento, o, desde la era industrial - y por medio de la masificación de la educación obligatoria - en un sistema para el desarrollo social, condicionamiento económico y político. La aceptación generalizada de la educación formal como criterio para medir la capacidad del individuo para integrarse en la sociedad, ha relegado a aquellos sin ella, a un plano inferior, socialmente y cognitivamente hablando. Metodologías educativas, desde la antigüedad en todo el mundo, han mantenido el paradigma de una separación entre los que "saben" y los que "no saben", creando así un "mandato u orden que alguien superior hace un inferior observar y guardar." Contrariamente a lo esperado, la masificación de la educación formal obligatoria no ha cambiado esto, sino que ha agravado esta situación. La falta de conocimiento de las personas que trabajan dentro del sistema educativo formal en lo que respecta al funcionamiento de los procesos de la vida y las estructuras -incluyendo los datos biológicos relativos al desarrollo fisiológico y neurobiológico- ha llevado a la creación masiva de los ciudadanos que se limitan sistemáticamente en su potencial humano, así como la discriminación regulado y generalizada de los que no tienen la certificación de haber completado su condicionamiento cognitivo, proceso que es, paradójicamente, la causa principal de la crisis educativa.

Palabras clave: educación, certificados, la neurociencia, la autopoiesis, la ignorancia, la educación obligatoria, la educación no formal, el currículo oculto, la información, el conocimiento, los especialistas, la comprensión, la experiencia, el cerebro, las etapas de desarrollo, Jean Piaget, Rebecca Wild, Humberto Maturana.

\section{ABSTRACT}

Formal education has been, throughout history a tool to maintain inequality and achieve social control either by lack of access to knowledge or since the Industrial Age-and also by means of the massification of compulsory education-in a system of conditioning social, economic and political aspects. The widespread acceptance of formal education as a yardstick to measure the individual's ability to integrate into society has relegated those without it to a lower stage, socially and cognitively speaking. Educational methodologies since ancient times have kept the paradigm of a separation between those who "know" and those who "don't know ," thus creating a "Mandate or order that someone superior makes an inferior observe and keep." Contrary to expectations, the massification of compulsory formal education has not changed this, rather, it has exacerbated this situation. The lack of knowledge of those who work within the formal educational system in regards to the functioning of life processes and biological structures-including the particulars related to physiological and neuro-biological development- This has led to the mass creation of citizens which are systematically limited in their human potential, as well as the regulated and generalized discrimination of those who do not have the certification of having completed their cognitive conditioning process, which is paradoxically, the main cause of the educational crisis. 230 words

Keywords: education, certificates, neuroscience, autopoiesis, ignorance, compulsory education, informal education, hidden curriculum, information, knowledge, specialists, understanding, experience, brain, development stages, Jean Piaget, Rebecca Wild, Humberto Maturana. 
Cuando hablamos de educación, comúnmente pensamos en la institucionalidad educativa -en las escuelas, en los colegios, en las universidades - en centros de estudio. Igual nos vienen a la mente materias o asignaturas a ser impartidas. En otras palabras, pensamos en lo que se conoce como "educación formal". ${ }^{1}$

Al pensar en educación formal, dejamos de lado el aprendizaje informal, aquel que ocurre automáticamente cuando nos relacionados con nuestro entorno. En nuestro mundo, lo formal es lo medible, mientras lo informal no lo es, y lo medible tiene un valor positivo, mientras lo no medible no tiene un valor reconocido o, por lo menos, no se lo considera útil.

Cuando hablamos de educación formal, nos referimos a un currículo que debe ser impartido, enseñado, transmitido: por ley, por derecho, por obligación social. Quien no ha sido educado formalmente, está imposibilitado de participar plenamente en la sociedad. Quien no tiene título - sea de bachiller, de licenciado, de maestría, o doctorado- es considerado como alguien que, de alguna manera, tiene impedimentos cognitivos inherentes a su persona que no le permiten integrarse a la sociedad. A estas personas se las considera "personas no-educadas," y se las ve como si tuviesen menos capacidad para vivir una

\footnotetext{
${ }^{1}$ Existen tres tipos de educación: la formal, la no formal y la informal. La educación formal hace referencia a los ámbitos de las escuelas, institutos, universidades, módulos. La educación no formal se refiere a los cursos, academias, e instituciones, que no se rigen por un particular currículo de estudios. La educación informal es aquella que fundamentalmente se recibe en los ámbitos sociales, pues es la educación que se adquiere progresivamente a lo largo de toda la vida. Wikipedia. Educación. Octubre 28, 2013 .

http://es.wikipedia.org/wiki/Educaci\%C3\%B3n
}

vida plena; sus oportunidades de subsistir y avanzar en la vida han sido, o serán mermadas, si no consiguen los certificados de haber pasado por la institucionalidad de una educación formal. Los seres humanos "no educados" tienen el estigma de ser parte de una clase social menos privilegiada. No se concibe que alguien que tenga la capacidad económica para ir a un centro educativo, no lo haga, a menos que tenga un problema psico-emocional.

Por otro lado, quien "más" educación formal tiene, es considerado un ciudadano más privilegiado por tener mayores conocimientos, mayores oportunidades de trabajo, y mejores posibilidades de ganarse la vida. Es como los individuos llegan a superarse, a "prepararse para el futuro" y ayudar a que el futuro de la sociedad sea mejor.

Más allá de esto, y a nivel macro, en el mundo de hoy la educación formal es considerada como la solución a los problemas del mundo. No obstante, si nos detenemos a pensar en todo esto, si hacemos algunas preguntas básicas, nos daremos cuenta de que nada de esto tiene sentido; no es científicamente comprobable, son puras suposiciones sin fundamento; inclusive, nos percataremos de que estamos incurriendo en errores de lógica, así como en inequidades sociales y en discriminaciones artificialmente creadas.

\section{Educación formal versus equidad} social

En primer lugar, la educación de una persona no se limita a lo aprendido en el tiempo que pasó educándose formalmente. La Educación -en mayúsculas- es más que una experiencia institucionalizada y refrendada por algún ente legal, sea este 
cual fuere, a pesar de la definición hacer pensar lo contrario:

Educación. (Del lat. educativo, - õnis). f. Acción y efecto de enseñar. 2. Crianza, enseñanza y doctrina que se da a los niños y a los jóvenes. 3. Instrucción por medio de la acción docente. $^{2}$

Si queremos dar una definición al concepto de educación que sea general y equitativa, basada no solo en los últimos doscientos años de institucionalidad educativa sino en el proceso educativo que viene dándose desde el principio de los tiempos (inclusive antes de que los mismos seres humanos estuviésemos caminado erguidos por el planeta, o que hayamos existido siquiera), podríamos decir que:

Educación es la adquisición y comprensión de experiencias y conocimientos por parte de organismos, y la subsiguiente transmisión de los mismos de individuos a individuos y de generación en generación.

En otras palabras, la educación no se limita a una "doctrina" que "se da" a los niños y a jóvenes (o adultos), sino que es una parte integral de la vida misma. La educación como un proceso de aprendizaje y transmisión de los conocimientos y sabidurías de la especie no es algo estrictamente antropocéntrico, pues está en nuestro ADN, y nuestro ADN proviene de nuestro pasado, inclusive desde cuando no existían más que unicelulares en nuestra Tierra. $^{3}$ Educación es parte de nuestro "ha-

\footnotetext{
${ }^{2}$ Real Academia Española, Diccionario de la lengua española, Vol. 1, Madrid, España Editorial Espasa Calpe, S.A., 2001, pp. 864.

${ }^{3}$ Los ciclos (o ritmos) circadianos son prueba de ello. La menstruación, por ejemplo, está basada en los ciclos lunares, los cuales dan fe a nuestros orígenes marítimos, de cuando la vida
}

cernos a nosotros mismos", es decir, es una realidad profundamente biológica.

Los conceptos de educación que se limitan a la enseñanza ${ }^{4}$ y a la adoctrinación, ${ }^{5}$ que se refirieren a la "transmisión de conocimientos, de principios e ideas", datan de fechas previas al descubrimiento de la transmisión de información genética, así como de las investigaciones sobre la neurología y la neurobiología. Estos conceptos ignoran totalmente los nuevos descubrimientos, conocimientos, y experiencias de las últimas décadas, manteniendo a la "doctrina de la educación formal" como una serie de preceptos inamovibles.

O sea, y como lo define el Diccionario de la lengua española, ${ }^{6}$ consideran a la educación como un "Mandato $\mathrm{u}$ orden que el superior hace observar y guardar al inferior o súbdito". ${ }^{7}$ Esto implica que:

Superior versus inferior $=$ inequidad.

Si miramos de cerca este fenómeno, nos daremos cuenta, inmediatamente, que los preceptos de la educación formal están basados no en el conocimiento del funcionamiento neurobiológico del ser humano, sino más bien en la ignorancia

surgió en las plataformas continentales y sus ciclos de procreación y nacimientos se regían por las mareas.

${ }^{4}$ Conjunto de conocimientos, principios, ideas, etc., que se enseñan a alguien. Diccionario de la lengua española, (pp. 925).

5 "Adoctrinar": instruir a alguien en el conocimiento o enseñanza de una doctrina, inculcarle determinadas ideas o creencias. "Doctrina": f. Enseñanza que se da para la instrucción de alguien. 2. Ciencia o sabiduría. 3. Conjunto de ideas u opiniones religiosas, filosóficas, políticas, etc., sustentadas por una persona o grupo. Diccionario de la lengua española, pp. 843.

${ }^{6}$ Diccionario de la lengua española, Vol. 2, pp. 1817.

${ }^{7}$ Itálicos del autor. 
de cómo es que los seres humanos (y otros organismos) aprendemos. Es decir, se basa no en una comprensión de cómo asimilamos los conocimientos y las experiencias para que estas lleguen a formar parte integral de nuestro organismo, sino en creencias e ideas sobre la enseñanza que provienen de épocas anteriores al Medioevo y que no tienen ningún sustento científico.

Cuando hablamos de ignorancia, debemos remontarnos al 399 a. C. -2400 años atrás-, a lo ocurrido con Sócrates, quien fue uno de los precursores de la idea de admitir nuestra ignorancia como punto de partida para encontrar respuestas a nuestras preguntas; es más, ipara encontrar las preguntas apropiadas!

\section{Sócrates - El descubrimiento de la} ignorancia

Los griegos habían ya hecho un largo recorrido desde el mundo de los mitos al mundo de las "causas impersonales", cuando Sócrates comenzó a preguntarse ${ }^{8}$ qué más existe, además de los elementos materiales; se dio cuenta de que la mente tiende a fabricar jugarretas, haciéndonos creer que algo es verdad, cuando es apenas una suposición.

Si bien nada de lo escrito por Sócrates sobrevivió, Platón logró salvar algo de la búsqueda insaciable que convirtió a Sócrates no solo en una de las figuras más famosas de la era dorada griega, sino en alguien que, por resaltar el grado de nuestra ignorancia, tuvo que morir.

${ }^{8}$ Daniel J. Boorstin,. The Seekers, The Story of Man's Continuing Quest to Understand His World. 1998, Londres: Phoenix Press. pp. 2123.
En esto no han cambiado mucho los tiempos. No obstante, son pocos quienes realmente hacen las preguntas más peligrosas hoy en día, menos aún quienes se atreven a revelar las verdades ocultas tras la ceguera colectiva que nos aqueja en muchas áreas, entre ellas en lo que concierne a la Educación.

Sócrates nació en Atenas hacia el año 499 a.C. Su padre fue un albañil o escultor. Si bien es posible que Sócrates comenzara trabajando con su padre, luego formó parte de la infantería armada, ya que no era un ciudadano suficientemente pudiente como para mantener un caballo y formar parte de la caballería. Su economía era suficiente para pagarse una armadura -el casco, la pechera, las grebas o canilleras, y aquel indispensable y pesado escudo de bronce-, así como las típicas armas de la época. ¿Por qué es esto importante?

Sócrates llegó a ser muy reconocido por su resistencia durante las luchas en la Gran Guerra del Peloponeso. ${ }^{9}$ Fue esto lo que dio a Sócrates su reputación. Su compañero de batalla, Laches, reportó que "si todos fueran como Sócrates, nuestra ciudad nunca habría llegado al desastre". ${ }^{10}$

Sócrates, hoy en día, tiene su fama por su facultad de razonamiento:

La sabiduría de Sócrates no consiste en la simple acumulación de conocimientos, sino en revisar

\footnotetext{
9 "La guerra del Peloponeso (431-404 a. C.) fue un conflicto militar de la Antigua Grecia que enfrentó a la Liga de Delos (conducida por Atenas) con la Liga del Peloponeso (conducida por Esparta). Wikipedia. Guerra del Peloponeso. Octubre 28, 2013.

http://es.wikipedia.org/wiki/Guerra_del_Pelopo neso.

${ }^{10}$ Boorstin, The Seekers, pp. 25.
} 
los conocimientos que se tienen y a partir de ahí construir conocimientos más sólidos.

Esto le convierte en una de las figuras más extraordinarias y decisivas de toda la historia; representa la reacción contra el relativismo y subjetivismo sofista, y es un singular ejemplo de unidad entre teoría y conducta, entre pensamiento y acción. A la vez, fue capaz de llevar tal unidad al plano del conocimiento, al sostener que la virtud es conocimiento y el vicio ignorancia. ${ }^{11}$

Sócrates rehusó participar en política, pues de hacerlo, decía, requeriría que dejara de lado sus principios. ${ }^{12}$

No obstante, a pesar de no tener una participación directa, sus posiciones personales y sus palabras de cuestionamiento no agradaron a quienes estaban en el poder. Fue miembro del Boule -o concejo legislativo-, una posición no política, parte de la labor ciudadana. ${ }^{13}$ Cuando un grupo de generales iban a ser juzgados en masa, él se paró en firme para que se lo hiciera de acuerdo a lo que dictaba la ley, o sea, individualmente. Un par de años más tarde, la oligarquía y quienes llegaron a ser conocidos como los Treinta Tiranos, ${ }^{14}$ quisieron implicar a Sócrates en sus actos de muerte judicial. Lo hubieran matado entonces, si no fuese porque la democracia fue re-instituida. ${ }^{15}$

\footnotetext{
${ }^{11}$ Wikipedia. Sócrates. Octubre 28, 2013. http://es.wikipedia.org/wiki/S\%C3\%B3crates.

${ }^{12}$ Boorstin, The Seekers, p. 25.

${ }^{13}$ Boorstin, The Seekers, p. 25.

${ }^{14}$ Wikipedia. Treinta Tiranos. Octubre 28, 2013.

http://es.wikipedia.org/wiki/Treinta_Tiranos.

${ }^{15}$ Boorstin, The Seekers, p. 25.
}

Su inconformismo lo impulsó a oponerse a la ignorancia popular y al conocimiento de los que se decían sabios, aunque él mismo no se consideraba un sabio, aún cuando uno de sus mejores amigos, Querefonte, le preguntó al oráculo de Delfos si había alguien más sabio que Sócrates, y la Pitonisa le contestó que no había ningún griego más sabio que él (Apología 21a). Al escuchar lo sucedido, Sócrates dudó del oráculo, y comenzó a buscar alguien más sabio que él entre los personajes más renombrados de su época, pero se dio cuenta de que en realidad creían saber más de lo que realmente sabían. Filósofos, poetas y artistas, todos creían tener una gran sabiduría, en cambio, Sócrates era consciente tanto de la ignorancia que le rodeaba como de la suya propia. Esto lo llevó a tratar de hacer pensar a la gente y hacerles ver el conocimiento real que tenían sobre las cosas. Asumiendo una postura de ignorancia, interrogaba a la gente para luego poner en evidencia la incongruencia de sus afirmaciones; a esto se le denominó «ironía socrática», la cual queda expresada con su célebre frase "Sólo sé que no sé nada". Su más grande mérito fue crear la mayéutica, método inductivo que le permitía llevar a sus alumnos a la resolución de los problemas que se planteaban por medio de hábiles preguntas cuya lógica iluminaba el entendimiento. Según pensaba, el conocimiento y el autodominio habrían de permitir restaurar la re- 
lación entre el ser humano y la naturaleza. ${ }^{16}$

Esto fue lo que finalmente llevó a que lo juzgaran, dándole la pena mayor:

La acusación, como lo reporta Jenofonte, declaró a Sócrates "culpable de no reconocer los dioses reconocidos por el Estado y por introducir otras, nuevas divinidades. También es culpable de corromper a la juventud. La pena demandada es la muerte". ${ }^{17}$

El asunto ese de los dioses, fue denegado por el mismo Sócrates, pero su oratoria durante el juicio deja entrever por qué lo acusaron de "corromper a los jóvenes":

Por otra parte, muchos jóvenes de las más ricas familias en sus ocios se unen a mí de buen grado, y tienen tanto placer en ver de qué manera pongo a prueba a todos los hombres que quieren imitarme con aquellos que encuentran; y no hay que dudar que encuentran una buena cosecha, porque son muchos los que creen saberlo todo, aunque no sepan nada o casi nada.

Todos aquellos que ellos convencen de su ignorancia la toman conmigo y no con ellos, y van diciendo que hay un cierto Sócrates, que es un malvado y un infame que corrompe a los jóvenes; y cuando se les pregunta qué hace o qué enseña, no tienen qué respon-

\footnotetext{
${ }^{16}$ Wikipedia. Sócrates. Octubre 28, 2013. http://es.wikipedia.org/wiki/S\%C3\%B3crates.

${ }^{17}$ Boorstin, The Seekers., p. 30.
}

der, y para disimular su flaqueza se desatan con esos cargos triviales que ordinariamente se dirigen contra los filósofos; que indaga lo que pasa en los cielos y en las entrañas de la tierra, que no cree en los dioses, que hace buenas las más malas causas; y todo porque no se atreven a decir la verdad, que es que Sócrates los coge in fraganti, y descubre que figuran que saben, cuando no saben nada. ${ }^{18}$

Así, por mantener su posición y sus principios, Sócrates murió envenenado con cicuta, método común en Grecia.

Murió a los 70 años de edad, aceptando serenamente esta condena, método elegido por un tribunal que le juzgó por no reconocer a los dioses atenienses y corromper a la juventud. Según relata Platón en la Apología que dejó de su maestro, éste pudo haber eludido la condena, gracias a los amigos que aún conservaba, pero prefirió acatarla y morir. ${ }^{19}$

Si pensamos que este tipo de comportamiento autoritario es cosa del pasado, una rápida mirada alrededor nuestro nos permitirá descubrir que estamos equivocados, especialmente cuando nos atrevemos a poner en velo de duda los preceptos considerados inamovibles de nuestra sociedad, aquellos paradigmas que, cuan-

\footnotetext{
${ }^{18}$ Apología de Sócrates al jurado de Jenofonte. La apologia de Sócrates. http://www.filosofia.org/cla/pla/img/azf01043.p df; Wikipedia. Apología de Sócrates (Jenofonte). Octubre 28, 2013 http://es.wikipedia.org/wiki/Apolog\%C3\%ADa de S\%C3\%B3crates_(Jenofonte).

${ }^{19}$ Wikipedia. Sócrates. Octubre 28, 2013. http://es.wikipedia.org/wiki/S\%C3\%B3crates.
} 
do quienes los soportan escuchan las críticas, reaccionan de manera similar a la corte que juzgó a Sócrates.

En el caso de la Educación, ¿cuáles son esos preceptos?

\section{Una breve historia de la educación}

Antes de la generalización en la sociedad de la educación formal, antes del advenimiento de la escritura, el conocimiento se lo adquiría por medio de la imitación y la observación, por medio de las experiencias vividas. ${ }^{20}$

El lenguaje - verbal y no verbalera la forma principal de transmitir los conocimientos de individua a individuo, y de generación en generación (sin dejar de lado el potencial genético para que esto ocurra).

Con la llegada de la división del trabajo en la era agrícola - que trajo consigo la creación de ciudades y grupos socioeconómicos definidos por sus actividades-, los "conocimientos tradicionales" fueron adquiridos por medio de "aprendizajes" prácticos, donde los jóvenes entraban en una relación de codependencia con sus maestros, trabajando para ellos a la vez que adquirían, así, sus habilidades.

Las estructuras formales de aprendizaje no llegaron hasta más tarde, principalmente en el área de las iniciaciones religiosas y sus rituales, prácticas que fueron asimiladas luego por las otras "profesiones" - como se las llamaría hoy en día-, creándose así los gremios de agricultores,

\footnotetext{
${ }^{20}$ Wikipedia. History of Education. Octubre 28, 2013.

http://en.wikipedia.org/wiki/History_of_educati on.
}

orfebres, albañiles, los trabajadores de textiles, los comerciantes, los filósofos, los recitadores, los guerreros, y así sucesivamente. Los secretos comerciales y de fabricación condujeron, inclusive y en ciertas áreas, a la creación de sociedades secretas para proteger este conocimiento, así como el derecho o "el poder de ejercer" y transmitir sus conocimientos.

Estas sociedades secretas surgieron tanto del área religiosa y sus "conocimientos divinos", así como de los llamados mannerbund, "bandas de guerreros" o "sociedades guerreras". ${ }^{21}$

Esto tal vez suene exótico, como una curiosidad histórica, pero de hecho ciertos colegios y universidades de hoy tienen justamente sus propias sociedades de estudiantes que se han considerado sociedades secretas ${ }^{22}$, como la Skull and Bones de la Universidad de Yale, $u$ otras que surgieron desde el siglo XIX en Harvard, en el Darmouth College, en la Universidad de Virginia y la de Nueva York; por ejemplo: el Pitt Club de la Universidad de Cambridge y el Bullington Club de la Universidad de Oxford

En tales sociedades secretas las condiciones para participar son claras:

1) Los conocimientos y el acceso a ellos por medio de estos gremios son exclusivos, es decir, no están abiertos a todos;

\footnotetext{
${ }^{21}$ Wikipedia. Secret Society. Octubre 28, 2013. http://en.wikipedia.org/wiki/Secret_society; $\mathrm{H}$. Schurtz, (1902). Alterklassen und Mannerbunde, Berlin; Reimer Verlag; A. Van Gennep, The Rites of Passage. (1961). Chicago: University of Chicago Press.

${ }^{22}$ Wikipedia. Secret Society. Octubre 28, 2013. http://en.wikipedia.org/wiki/Secret_society.
} 
2) Dicen tener secretos especiales;

3) Muestran un fuerte favoritismo hacia quienes forman parte de este gremio.

Si vemos la correlación entre estos gremios, y el fenómeno social de lo que se conoce como "la educación formal", vemos que la sociedad favorece a quienes "tienen los conocimientos" y desfavorece a quienes carecen de ellos. Está claro que se han creado una especie de gremios dentro de gremios-los especialistas en ingeniería y los especialistas de la economía, los especialistas en leyes (el gremio de los abogados) y los especialistas de la salud (el gremio de los médicos y los doctores); inclusive nos encontramos frente al "gremio de los educadores" con sus propios certificados de pertenecer a un grupo exclusivo de quienes tienen el "derecho de impartir conocimientos". En ciertas sociedades, quien no tiene su título de haber pasado por el sistema educativo formal, no podrá entrar a ejercer no solo su profesión, sino que tampoco podrá trabajar como un educador en su área de expertise.

Pero nos estamos adelantando a la historia.

La transmisión del conocimiento formal comenzó con el desarrollo de los sistemas de escritura, hacia el año 3500 a.C. El alfabeto más antiguo conocido proviene de Egipto, hacia el año 2000 a.C., con sus jeroglíficos. Eran pocos quienes, además, tenían el derecho de plasmar en arcilla, piedra, cuero o papiros, las palabras o símbolos que representaban cosas, ideas, conceptos. Sin embargo, y sin entrar en la historia del desarrollo de la lecto-escritura, quienes tenían acceso a esta -la madre de todos los conocimientos-, obviamente acabaron en posiciones privilegiadas. De hecho, los primeros textos a ser escritos fueron los textos sagrados, las épicas de los dioses (la Épica de Gilgamesh de la antigua Mesopotamia fue una de las primeras obras de la literatura en ser inscritas). Inclusive hoy en día -o más que nunca, en estos tiempos, en la Era de la Información-, el punto de partida para adquirir cualquier tipo de conocimiento reconocido formalmente es, precisamente, saber leer y escribir.

En el antiguo Egipto, ${ }^{23}$ la alfabetización estaba concentrada entre las élites educadas de los escribanos. Solo personas con trasfondos sociales especiales tenían permiso de estudiar a ser escribanos; aquellos al servicio de los templos y de los faraones, así como los militares.

En la antigua India, ${ }^{24}$ entre los años 1500-600 a.C., la educación estaba concentrada en aprender los himnos y las fórmulas -las Vedas - que recitaban los clérigos, e inclusive luego de que ya se abrió este conocimiento a la población, quienes tenían acceso a esta educación y a los conocimientos impartidos eran aquellos que formaban parte de los estratos más altos en el sistema de castas sociales.

En China ocurrió algo parecido. ${ }^{25}$ Durante la Dinastía Zhou (1045-256 a.C.), las escuelas eran exclusivamente para el uso de los aristócratas y la nobleza; allí se enseñaban los Seis Artes: los ritos, la músi-

\footnotetext{
${ }^{23}$ Wikipedia. History of Education. Octubre 28, 2013.

http://en.wikipedia.org/wiki/History_of_educati on.

${ }^{24}$ Wikipedia. History of Education. Octubre 28, 2013.

http://en.wikipedia.org/wiki/History_of_educati on.

${ }^{25}$ Wikipedia. History of Education. Octubre 28, 2013.

http://en.wikipedia.org/wiki/History_of_educati on.
} 
ca, la arquería, el manejo de las aurigas, la caligrafía y las matemáticas. Los conocimientos debían ser impartidos de acuerdo a las edades (para los doce, los niños debían ya haber dominado los rituales de la música y la danza, para luego pasar a la arquería y al manejo de las aurigas; mientras que las niñas, además de los rituales, debían aprender la conducta correcta, cómo producir la seda y cómo el arte de tejer).

Se puede decir que la nobleza y la aristocracia podían dedicar su tiempo a estas actividades no productivas, mientras que los demás ciudadanos y súbditos tenían como función social la producción de vestimentas, herramientas y alimentos, para mantener a la sociedad $y$, especialmente, para con su trabajo productivo mantener el estatus quo de las clases sociales gobernantes.

En Grecia y en Roma, la mayoría de la educación era privada y revolucionaria, en el sentido que inclusive los pobres intentaban dar tiempo a que sus hijos fueran a una escuela. Aparte de las obligaciones hacia el Estado - dos años de entrenamiento y servicio militar-, cualquiera tenía el derecho de abrir una escuela y decidir en el currículo. Esto fue, en cierto modo, lo que llevó a que quienes tuviesen dinero para pagar por ello: contrataran tutores entre quienes se consideraban sabios. Así, ciertos sabios como Sócrates, abrieron espacios para el aprendizaje que incluía la gimnasia, el atletismo y otros deportes, así como la música, la poesía, el drama, la historia y ... la alfabetización.

Las niñas, por cierto, rara vez tenían oportunidad de participar en esto.
No obstante, a pesar de esta "libertad", tan solo los más pudientes podían darse el lujo de que sus hijos continuaran estudiando en materias tales como retórica, matemática, historia natural, política, lógica (el centro más conocido siendo el Liceo de Atenas, fundado por Platón), mientras que los menos pudientes debían conformarse con enviar a sus hijos a que hicieran aprendizajes con artesanos.

Se considera que el grado de alfabetización en la Roma del siglo XXX a.C., estaba alrededor del uno al dos por ciento, la mayoría y ya entrando al tiempo de la República Romana, ocurriendo en centros privados. En aquella época, la educación superior no era más que una manera de demostrar el estrato social del cuál uno provenía, es decir, y en términos prácticos, principalmente un aspecto de estatus más que de aplicaciones concretas a la vida diaria.

Durante la Edad Media, los monasterios fueron los principales centros del conocimiento y la alfabetización, y por ello el aprendizaje estaba íntimamente ligado a los valores religiosos. Las primeras instituciones, precursoras de las universidades del presente, fueron fundadas hacia el siglo XIV d.C., mientras que aquellas que ya se consideraron ser universidades -en Italia, Francia e Inglaterra-, comenzaron a aparecer entre el siglo XI y XII, principalmente para transmitir los conocimientos de arte, medicina, leyes y teología.

Sin entrar en los detalles del contenido de las materias - basadas en los valores religiosos, militares y fundamentas en las estructuras de poder y obediencia-, podemos ver cómo el concepto de educación no solo que contenía una estructura jerárquica (de quienes saben, enseñando a 
quienes no saben o saben menos), sino de que la idea de que la acumulación de conocimientos y destrezas era una manera para llegar a ser parte de los estratos sociales altos de la clase pudiente.

Fue en el año de 1179, durante el Tercer Concilio Lateranense ${ }^{26}$ celebrado en Roma, convocado por Alejandro III (considerado por la Iglesia Católica como el XI Concilio Ecuménico), que entre muchos puntos de orden, los curas dieran la oportunidad a sus feligreses de "ser educados", mientras que el Movimiento Escolástico de los siglos XII y XIII, fue lo que dio pie a que la educación se regara por los otros estratos sociales entre las ciudades europeas. ${ }^{27}$

La historia de la educación es sumamente compleja, pero en muchas partes del mundo tienen algo en común: el sentido de exclusividad, así como de una relación directa con las estructuras de poder (el mayor siendo, en la mayoría de los casos, el poder religioso y el de la clase noble).

Resulta que no fue hasta hace unos doscientos años, con la llegada de la Revolución Industrial, que la educación pasó a ser no solo un derecho de todos los integrantes de la sociedad - accesible, también, para la llamada "clase trabajadora"-, sino una obligación impuesta por los gobiernos. Algunos podrán decir que con esto cambió el paradigma social, otorgando igualdad a todos los ciudadanos, pero no

\footnotetext{
${ }^{26}$ Wikipedia. Concilio de Letrán. Octubre 28, 2013.

http://en.wikipedia.org/wiki/History of educati onhttp://es.wikipedia.org/wiki/Concilio_de_Letr $\% C 3 \%$ Aln III.

${ }^{27}$ Wikipedia. History of Education. Octubre 28, 2013.

http://en.wikipedia.org/wiki/History_of_educati on.
}

fue así. Los intereses de quienes manejan la política - de manera abierta o encubierta - no ha cambiado. La pregunta que no se debe hacer - ¿Cómo mantener la exclusividad y el acceso casi imperecedero al poder, si todos los ciudadanos tienen acceso al conocimiento, antes limitado a las clases altas y a los clérigos?-cambió de piel, más no de cuerpo.

En primer lugar, el poder se mantiene no solo por el contenido de los conocimientos compartidos, sino por las "relaciones sociales" a las que se exponen los alumnos al formar parte de las instituciones más exclusivas - $-\mathrm{y}$ costosas - del planeta. En segundo lugar, por algo que se conoce como el "currículo oculto". En tercero, el resultado final de la educación formal-sin importar la clase social-, depuraba la rebeldía. En pocas palabras, sin importar la profesión o el contenido de las carreras, el sistema educativo aseguraba que los ciudadanos acataran y se alinearan a los mandatos sociales y políticos, mostrando su pasiva conformidad con los mismos, pero más allá de ello, la continuidad del sistema vigente y el sometimiento ante sus valores, ante todo el valor oculto de la obediencia.

A nivel individual, el título es indicativo que el proceso de formación ha culminado. Es un "certificado de obediencia" de que los preceptos del currículo han sido asimilados. El nivel de educación, representado por categorías de mayor valor en orden ascendente - bachillerato, licenciatura, maestría, doctorado-, dan fe del grado de especialización ${ }^{28}$. Como la palabra

\footnotetext{
28 "Especializar. Limitar algo a uso o fin determinado. 2. Cultivar con especialidad una rama determinada de una ciencia o de un arte." Diccionario de la lengua española, Vol. 1, pp. 975. $\mathrm{O}$ sea, quienes se consideran ser especialistas,
} 
mismo lo indica, no solo que socialmente se considera a alguien como "especial" (con connotaciones de que es "mejor" que los demás, es decir, con cualidades de ser especial, lo cual implica un sentimiento de superioridad), sino que, por otro lado, el especialista ${ }^{29}$ se limita a algo en específico. Es decir, mientras mayor el grado de especialidad y de estudios, mayor es la limitación a la que ha sido expuesta un estudiante. El título no es indicativo del grado de humanidad de una persona, o de sus capacidades como ser humano o ciudadano, o de su conocimiento general, sino de su orientación y restricciones cognitivas gracias a una profundización en un área específica, y por seguir los preceptos aceptados por cada gremio.

Así, no se espera que un especialista en tratamientos químicos para la limpieza del horizonte productor de un pozo petrolero sepa de las estrategias reproductivas de las hormigas Leptogenys del Parque Nacional Yasuní. Asimismo no se espera que un PhD en educación sepa sobre los procesos de mielinización de las dendritas causada por decisiones autónomas, o sobre la comunicación entre las neuronas del corazón y las del cerebro, a pesar que es justamente este conocimiento (entre otros parecidos) lo que permitiría saber cómo aprendemos.

De esta manera se departamentaliza y restringe el derecho de conocer (y por ende opinar) sobre una cierta rama del conocimiento, mientras que a su vez se confina a "niveles inferiores", social y económicamente hablando, a quienes no

son personas que han limitado sus conocimientos a un área específica.

${ }^{29}$ Especialista. Que cultiva o practica una rama determinada de un arte o ciencia. Diccionario de la lengua española, Vol. 1, p. 975. cuentan con su certificado, o cuyo certificado implica un "menor rango educativo", lo cual, a su vez, reduce las oportunidades de quienes no han pasado por la formación de una educación formal. Más allá de esto, inclusive el origen (o pedigrí) de la institución educativa crea sus propias barreras de entrada a la sociedad y sus estratos sociales, siendo aquellas de Primer Mundo, las que se encuentran en la cúspide planetaria.

\section{La ilusión del conocimiento y el currículo oculto}

Las barreras de entrada a la sociedad no se limitan al grado de educación de los individuos y a la entidad emisora de los certificados, sino que además existen elementos disimulados no solo en el contenido de los currículos, sino en cómo y dónde así como en las condiciones bajo las cuales se adquieren los "conocimientos".

En primer lugar, vivimos con la ilusión de que el conocimiento es indispensable para vivir en el mundo actual. Si bien puede ser indispensable, no lo es todo.

La confusión principal radica en la idea de que la "información" es igual al "conocimiento", que conocer es igual que comprender, y que "tener conocimiento" puede inclusive suplantar a la experiencia.

De manera abierta o encubierta, directa o indirecta, la experiencia (o la falta de la misma) es clave para la formación -o mal-formación - de nuestras habilidades y potenciales humanos. Antes de entrar en cuál es la experiencia de quienes han sido expuestos a la educación formal, no obstante, tal vez procede comprender la razón por la cuál se consideró como necesaria la masificación de la educación, a pesar de 
que aparentemente iba en contra de los intereses de quienes manejan los puestos de poder.

La Iglesia, podría decirse, descubrió primero que "educar" a los feligreses le otorgaba poder. La Iglesia de Escocia creó una reforma en enero de 1561 donde debía haber un profesor de escuela en cada parroquia para educar a los pobres. Esto luego se corroboró en 1633 por medio del Acto del Parlamento de Escocia, que introdujo un impuesto para mantener este programa. Descubrieron - si bien posiblemente no de forma consciente-, que la formación escolar proveería de súbditos cuyas ideas se asemejarían más a los ideales y a las creencias religiosas y gubernamentales.

De hecho, en el año de 1760, Ivan Beskoy fue nombrado asesor de educación por Catalina II-la zarina de Rusia-, para instaurar un sistema educativo que permitiría "crear una nueva raza de hombres". ${ }^{30}$ Los argumentos presentados fueron varios, entre ellos la necesidad de una educación general y no especializada, puesto que "al regenerar nuestros sujetos por medio de una educación fundada en estos principios, crearemos nuevos ciudadanos".

No es coincidencia, por lo tanto, de que la educación formal comenzara a convertirse en obligatoria. Era, a su vez, el comienzo de la Revolución Industrial. Esta (la Revolución Industrial) se caracteriza por la transición a nuevos métodos de manufactura - de una producción manual y artesanal, al uso de la máquinas y a la sistematización de los procesos de manufactura-, un fenómeno que comenzó oficialmente

\footnotetext{
${ }^{30}$ Wikipedia. History of Education. Octubre 28, 2013.

http://en.wikipedia.org/wiki/History_of_educati on.
}

entre los años de 1760 a 1840. Más allá de un cambio en la forma de manufacturar productos, y de sus beneficios para la sociedad, la Era Industrial requirió de un cambio de matriz energética - de la fuerza del agua y el viento, así como del uso de biocombustibles, al uso de otros combustibles como los fósiles (principalmente carbón, luego petróleo)-, así como de un cambio radical en la matriz laboral.

Las grandes fábricas requirieron "nuevos ciudadanos" con cualidades específicas. Entre las principales cualidades, encontramos: la obediencia (acatar las órdenes de capataces), la puntualidad (que ya se vino instituyendo en el mundo religioso con el descubrimiento del reloj, considerado como la madre de todas las máquinas), y el trabajo repetitivo demandado por las máquinas de manufactura ... en su mayoría bajo condiciones sub-humanas (que no debían ser cuestionadas).

Además de la inequidad económica (sobre la cual Karl Marx-1818-1883-, y otros contemporáneos demandaron), creada en gran medida por el "factor de escala" y la "capacidad adquisitiva" de la fuerza laboral (versus la de quienes sacaron el verdadero provecho de esta revolución), el currículo oculto de este nuevo modelo educativo (los unos aprendiendo a trabajar con las máquinas, los otros a manejar a las masas de obreros) requirió, además, de un nuevo "modelo educativo", puesto que los adultos ya no podían hacerse cargo de sus hijos, y los hijos debían prepararse para cuando llegaran a ser adultos para poder adaptarse, lo más rápido posible, a las nuevas modalidades de trabajo. Por otro lado, el modelo industrial trajo como secuela la idea de que así como podían manufacturar bienesherramientas, vestimentas, maquinarias, 
etc.-en masa, igualmente se podría llegar formar y a masificar la fuerza laboral, como un efecto secundario subrepticio, también conocido como el "currículo oculto".

El currículo oculto trata de "los efectos secundarios de la educación". ${ }^{31}$

Se llama currículo oculto a aquellos aprendizajes que son incorporados por los estudiantes aunque dichos aspectos no figuren en el currículo oficial. Según las circunstancias y las personas en contacto con los estudiantes dichos contenidos pueden o no, ser "enseñados" con intención expresa. Cualquier entorno, incluso actividades sociales y recreacionales tradicionales, pueden brindar aprendizajes no buscados ya que el aprendizaje se vincula no solo a las escuelas sino también a las experiencias por las que pasa una persona (sean estas escolares o no). ${ }^{32}$

${ }^{31}$ Wikipedia. History of Education. Octubre 28, 2013.

http://en.wikipedia.org/wiki/History_of_educati on. Wikipedia. Currículo oculto. Octubre 28, 2013.

http://es.wikipedia.org/wiki/Curr\%C3\%ADculo oculto.

${ }^{32}$ Frecuentemente, currículo oculto se refiere a conocimientos adquiridos en las escuelas primarias y secundarias, normalmente con una connotación negativa producto de la forma subrepticia de influir sobre personas en formación. Por ejemplo, generan rechazo los objetivos de algunos sistemas educativos de promover el desarrollo intelectual con ciertos sesgos, o la acción de personas asociadas a corrientes ideológicas determinadas que utilizan su posición para influir sobre el desarrollo de sus estudiantes e inducirlos a adherir a puntos de vista afines a su posición ideológica.2 En este contexto el currículo oculto puede reforzar las desigualdades sociales existentes mediante la enseñanza de temas y comportamientos en función de la clase y estatus social de los estudiantes, o puede servir como una herramienta para manipular estu-
No es gratuito, entonces, que por esos mismos años -1770-, algunas personas comenzaran a investigar el tema de las metodologías educativas y sus sistematización, así como su efecto en la socie$\operatorname{dad}^{33}$ - los efectos deseados, y los no deseados.

Alemania creó la primera "presidencia pedagógica" en la Universidad de Halle, ${ }^{34}$ con lo que las metodologías educativas comenzaron a formar parte del concepto de comprender cómo es que el ser humano aprende. Aparecieron especialistas en la educación (pedagogos), algunos de los cuales pidieron reformas educativas, tales como Johann Heinrich Pestalozzi, en Suiza, Joseph Lancaster en Gran Bretaña, y Wilhelm von Humbolt fundó una nueva universidad en Berlín en 1810 para crear

diantes induciéndolos hacia organizaciones foráneas al ámbito educativo (religiosas, políticas..).3 El currículo oculto puede hacer referencia también a la transmisión de normas, valores y creencias que acompañan a los contenidos educativos formales y a las interacciones sociales en el seno de estos centros educativos. El concepto que expresa el currículo oculto es la idea de que los centros educativos hacen más que la simple transmisión de conocimiento, que establecen los currículos oficiales. Tras esto subyace el tema de las implicancias sociales, los cimientos políticos y los productos culturales de las actividades educativas modernas. Mientras que las primeras aproximaciones trataron de identificar la naturaleza antidemocrática escolar, estudios posteriores han tomado distintos matices, incluidos los referidos al socialismo, el capitalismo, y el anarquismo en la educación.

Wikipedia. Currículo oculto. Octubre 28, 2013. http://es.wikipedia.org/wiki/Curr\%C3\%ADculo oculto.

${ }^{\overline{3} 3}$ Wikipedia. Industrial Revolution. Octubre 28, 2013.

http://en.wikipedia.org/wiki/History_of_educati onhttp://en.wikipedia.org/wiki/Industrial_Revol ution.

${ }^{34}$ Wikipedia. History of Education. Octubre 28, 2013.

http://en.wikipedia.org/wiki/History_of_educati on 
un modelo de "universidad de la investigación".

Así, hacia finales del siglo XIX, aparecieron escuelas abiertas a toda la población, inclusive bajo orden gubernamental, para una obligatoriedad de asistencia, porque los políticos creían que se requería de esto para conseguir "un comportamiento político ordenado", 35 mientras que, por otro lado, los dueños de las fábricas se dieron cuenta de que su productividad podría mejorarse con "personal calificado". Si además de esto consideramos que en muchas ocasiones los poderes políticos y los económicos eran uno y el mismo, no debe sorprendernos el hecho de que se haya instituido la obligatoriedad de la educación formal, así como la creación de privilegios para quienes lograran llegar a los estratos más altos en el nivel educativo.

Parte integral del currículo oculto es justamente la "creación de efectos secundarios diferenciados" en la forma (y en los contenidos) de quienes están siendo educados para: a) trabajar con las máquinas, b) quienes se preparan para administrar el personal, y c) quienes acaban como propietarios.

Hacia el final de la Segunda Guerra Mundial aparecieron nuevas propuestas educativas, entre ellas, el método de María Montessori, ${ }^{36}$ en Italia; las escuelas de Ru-

\footnotetext{
${ }^{35}$ Wikipedia. History of Education. Octubre 28, 2013.

http://en.wikipedia.org/wiki/History_of_educati on.

${ }^{36}$ Wikipedia. History of Education. Octubre 28, 2013.

http://en.wikipedia.org/wiki/History_of_educati on. Wikipedia. History of Education. Octubre 28, 2013; Wikipedia. María Montessori. Octubre 28,2013

http://en.wikipedia.org/wiki/Maria_Montessori / http://es.wikipedia.org/wiki/Maria_Montessori.
}

dolf Steiner y su método Waldorf, en Alemania; el sistema de Summerhill ${ }^{37}$ de A.S. Neill, en Inglaterra; los transcendentalistas Amos Bronson Alcott y Ralph Waldo Emmerson, así como Henry David Thoreau, en Estados Unidos. De hecho, la lista de "alternativas educativas" es bastante larga y diversa, con posiciones ya sea religiosas, políticas, o simplemente inconformistas hacia la educación existente.

Anarquistas como Leo Tolstoy y Francisco Ferrer Guardia, veían a la educación como una fuerza para la liberación política y secular, así como para la eliminación de las clases sociales. Ivan Illich, y otros críticos sociales, examinaron la educación desde puntos de vista de los efectos de la educación convencional como una manera de subvertir a la democracia, mientras que otros educadores como Paulo Freire, Herbert Kohl y Jonathan Kozol, criticaron la educación occidental por sus tendencias derechistas, contrarias a los ideales considerado izquierdistas, o de inclusión social.

Este tipo de alternativas, sin embargo, no han sido bien vistas por el sistema formal, ya que en ellas subyace una corriente que va en contra de los últimos miles de años de preceptos educativos, donde las clases sociales, el poder económico, y las posiciones políticas, se basan aún en estructuras jerárquicas que contemplan la superioridad de unos sobre otros.

Esto, en cierto modo, llevó a las revoluciones sociales y económicas que marcaron la historia del siglo XX, así como mu-

\footnotetext{
${ }^{37}$ Wikipedia. Summerhill School. Octubre 28, 2013. http:/len.wikipedia.org/wiki/Summerhill_School
} 
chas de sus guerras y rebeliones. Sin embargo, y a pesar de estas revoluciones, así como de ciertos cambios en la metodología educativa (por ejemplo, la prohibición de las agresiones físicas de profesores a alumnos), el concepto de educación sigue siendo el mismo, y el currículo oculto se mantiene oculto.

\section{"Crisis planetaria", "crisis educati- va" y "crisis institucional"}

La manera como accedemos a la educación, si es estatal o privada, si es accesible a los niveles económicos bajos o no, automáticamente tiene efectos sociales por asociación. Las mismas hermandades universitarias, mencionadas antes, que en ocasiones desembocan en sociedades secretas, tienen el efecto de que quienes forman parte de estas, y entran a puestos de poder, favorecerán a quienes hayan sido parte de su "círculo fraternal" para obtener puestos de trabajo o posiciones políticas. Este "conocimiento oculto" es, justamente, una de las bases para mantener las estructuras de poder social, económico y político.

Es decir, la educación, y los entornos sociales a los cuales estamos expuestos (inclusive el tipo de información que se transmiten a los educandos), tiene una relación directa con las expectativas sociales e institucionales de cada alumno.

De este modo, quien haya estudiado en Harvard tiene otras posibilidades económicas y sociales que alguien proveniente de la universidad de Loja, en Ecuador, o cuyo título haya sido adquirido por estudios a distancia en alguna universidad "en línea" de la cual pocos han oído. Inclusive si los currículos fuesen estrictamente los mismos, la mera asociación a un centro educativo u otro ya abre -o cierrapuertas y puestos de trabajo, así como las expectativas de superación social.

Sin embargo, y sin importar en dónde se ha estudiado, la "metodología educativa" sigue siendo la misma, es decir, una metodología basada en la idea de que aprender, y enseñar, son "lados opuestos de una misma moneda".

En su mayoría, los métodos educativos formales, más allá de una inclusión o exclusión social, de los ideales políticos y/o económicos, ignoran por completo el funcionamiento del cerebro más allá de su capacidad de memorizar y razonar. Es más, desconocen completamente (hasta el punto de rechazar) la existencia de "procesos de vida" y de "estructuras biológicas y neuro-biológicas" que nos caracterizan a todos los seres humanos, no importa de qué cultura provengamos, a qué nivel social pertenezcamos, con cuál corriente ideológica nos asociemos, o en qué idioma hablemos. La metodología misma de la educación formal no permite un desarrollo cognitivo interconectado.

Es decir, la mera acumulación de información y conocimientos, no garantiza una compresión de cómo funciona el mundo. La "departamentalización del conocimiento"-el divorcio entre la teoría y la práctica y la falta de interconexión entre las asignaturas, así como la creencia que el aprendizaje requiere de un conductivismo externo para que funcione-, impiden reconocer las consecuencias de las acciones humanas en los sistemas complejos planetarios.

Por lo tanto, la "crisis de la educación" va a la par con las crisis planetarias: con las degradaciones de los niveles eco- 
nómicos, con los problemas ambientales, con la corrupción política así como con tantos otros "problemas" los cuales, en el fondo, no son más que los síntomas y las secuelas de un sistema educativo que si bien tal vez logra impartir conocimiento, no es apto para "transmitir comprensión".

El divorcio del conocimiento adquirido con la realidad física y biológica del planeta, - con lo que se conoce como el "flotante de cambios radicales"-, es la principal causa de ello, así como de la crisis institucional que se considera ya habitual, normal, inclusive irremediable y parte cotidiana de nuestras vidas. nómeno: ${ }^{38}$

Una corta lista ejemplifica este feSistemas judiciales sin justicia.

Universidades que han dejado de ser universales.

Economías que no pueden economizar.

Corporaciones que no pueden cooperar ni competir, tan solo consolidar.

Policía que no puede hacer cumplir las leyes.

Sistemas de ayuda médica... enfermos.

Gobiernos que no pueden gobernar.

Escuelas que no pueden enseñar.

Sistemas agrícolas que destruyen el suelo y envenenan el alimento.

Como lo explica Dee Hock, en su libro El nacimiento de la Era Caórdica, ${ }^{39}$ el

\footnotetext{
${ }^{38}$ Dee Hock, Birth of the Chaordic Age. San Francisco, Berret-Koehler Publishers, Inc. 1999. pp. 28-29.
}

principal problema radica en lo que se conoce como el "flotante de cambio" versus el "flotante institucional". El flotante de cambio no es más que el tiempo que se requiere para que un fenómeno llegue a su culminación.

También se lo conoce como "histéresis", ${ }^{40}$ el tiempo que demora para que un fenómeno llegue a afectar el ambiente sobre el cual -o en el cual-ocurre este fenómeno. Existen varios tipos de histéresis (originalmente utilizado para describir el comportamiento de materiales magnéticos pero también aplicable a la economía, la biología, entre otros), ${ }^{41}$ pero lo que nos interesa es cuánto tiempo demora un cambio en afectar al ambiente o entorno dentro del cual ocurre este cambio.

Como lo apuntó el futurista James Burke, tomó siglos para que la información sobre la fundición del hierro se regara por un solo continente con lo cual llegó la Era del Hierro. En la época de los barcos veleros, tomó décadas para que lo que se sabía se convirtiera en lo que se compartía. Cuando el hombre puso el pie en la Luna, se conoció de este hecho en cada esquina de nuestro planeta 1,4 segundos más tarde. Sin embargo esto es desesperanzadamente primitivo. Hoy en día, eventos inconta-

\footnotetext{
${ }^{39}$ Dee Hock, Birth of the Chaordic Age, pp. 104-105.

${ }^{40}$ Wikipedia. Hysteresis. Octubre 28, 2013. http://en.wikipedia.org/wiki/Hysteresis / Wikipedia. Histéresis. Octubre 28, 2013. http://es.wikipedia.org/wiki/Hist\%C3\%A9resis ${ }^{41}$ Wikipedia. Hysteresis. Octubre 28, 2013. http://en.wikipedia.org/wiki/Hysteresis Lecciones de Electrónica. Capítulo VII, Magnetismo. Octubre 28, 2013./

http://www.ifent.org/lecciones/cap07/cap0706.asp /
} 
bles en cualquier lado se escuchan y ven instantáneamente en todo lado.

Más importante aún es la desaparición del flotante científico y tecnológico: el tiempo entre un descubrimiento de nuevo conocimiento, la tecnología que resulta del mismo, y su aplicación universal. Tomó siglos para que la rueda, uno de los primeros inventos tecnológicos, ganara aceptación universal -décadas para la máquina de vapor, la energía eléctrica, y el automóvil-, años para la radio y la televisión. Hoy, incontables dispositivos con microchips se extienden por el mundo como la luz del sol hacia su uso universal. ${ }^{42}$

Sin embargo, y a pesar de todos estos cambios y descubrimientos, el "flotante institucional" (el tiempo que demora para que las instituciones cambien sus estructuras organizativas) se mantiene relegado al principio de la Era Industrialinclusivo mucho antes, al advenimiento de la burocracia en Mesopotamia hace ya cerca de nueve mil años-, con sus estructuras jerárquicas y su extraordinario poder de dilación. Por un lado, la información puede fluir instantáneamente en nuestros días y, sin embargo, hasta que un evento ocurra basado en la nueva información, transcurren días, semanas, inclusive años. (El sistema judicial es perfecto ejemplo de ello.)

Es más grave aún este fenómeno cuando nos enfrentamos al "flotante educacional".

\footnotetext{
${ }^{42}$ Hock, Birth of the Chaordic Age, pp. 104-
} 105.
El flotante educacional actual mantiene metodologías de enseñanza provenientes del tiempo de los griegos, con prácticas y metodologías pedagógicas sistematizadas durante la Revolución Industrial (para la masificación de "ciudadanos formados"), y se inspira en los preceptos de la psicología conductista ${ }^{43}$ de B. F. Skinner, ${ }^{44}$ y su condicionamiento para conseguir resultados medibles que han desembocado en la "ingeniería del comportamiento".

El modelo conductista prácticamente toma al ser humano ( $y$ a los animales) como seres programables, como envases a los cuales se los alimenta con información y conocimientos, cuyos resultados (y avances) pueden ser medidos por medio de evaluaciones periódicas (los exámenes y las pruebas).

Mientras tanto, los descubrimientos de la neurociencia (que comenzaron a aparecer de manera regular a partir del siglo $\mathrm{XVI}{ }^{45}$ pero que no vieron su boom hasta los principios del siglo XX con su explosión inusitada de descubrimientos más de 500.000 por año- a partir de la

\footnotetext{
${ }^{43}$ Wikipedia. Psicología conductista. Octubre 28, 2013.

http://es.wikipedia.org/wiki/Psicolog $\% C 3 \% A D a$ conductista / Wikipedia. Conductismo. Octubre 28, 2013.

http://es.wikipedia.org/wiki/Conductismo /

Skinner, B. (1974/1977). Sobre el conductismo. Barcelona: Fontanella.

${ }^{44}$ Wikipedia. B. F. Skinner. Octubre 28, 2013.http://en.wikipedia.org/wiki/B._F._Skinner /Wikipedia. Burrhus Frederic Skinner. Octubre 28, 2013.

http://es.wikipedia.org/wiki/Burrhus_Frederic_ Skinner.

${ }^{45}$ Wikipedia. History of neuroscience. Octubre 28, 2013.

http://en.wikipedia.org/wiki/History_of_neurosc ience.
} 
segunda mitad del mismo siglo ${ }^{46}$ ), no fueron considerados suficientemente importantes como para aplicarlos al aprendizaje regular, sino, más bien, como una manera para reconocer y diagnosticar enfermedades mentales.

No obstante, si se tomaran estas investigaciones y se las aplicara a la educación, en conjunto con una filosofía de "respeto a los procesos de vida", no se podría continuar con las metodologías educativas predominantes.

\section{Las bases biológicas del aprendiza-} je

El ser humano es un ser biológico. Negar esto es absurdo. Los sistemas biológicos -los organismos vivos-, basan su existencia en los "fundamentos de los sistemas vivos", algo que Humberto Maturana -neurobiólogo chileno- definió como autopoiesis o, "el hacerse a sí mismo". ${ }^{47}$

\footnotetext{
${ }^{46}$ De hecho, algunas de estas investigaciones, ya en los años 60, descubrieron que la mielinización de las dendritas - el recubrimiento de mielina que permite la eficiente y correcta transmisión de las señales neurológicas entre neuronas - ocurre en mayor cantidad cuando las decisiones de movimientos motrices provienen desde dentro (es decir, son voluntarias y no inducidas desde fuera), se complementan con descubrimientos posteriores de relaciones de comunicación entre el cerebro y el corazón que recorren las estructuras cerebrales trinas (reticular, límbico y corteza cerebral), siempre y cuando las decisiones de actuar provengan desde el interior del organismo.

Sin embargo, a pesar de la existencia de este tipo de descubrimientos, su aplicación en el ámbito educativo quedan ausentes cuando se discuten los problemas de la "crisis educativa" o cuando se buscan aparentes soluciones a la problemáticas sociales.

${ }^{47}$ Francisco Varela, Humberto Maturana $E l$ árbol del conocimiento. México D.F., Editorial Lumen, 2004.
}

La autopoiesis implica la existencia de estructuras biológicas que separan lo vivo de lo no vivo, la vida de lo inerte.

La autopoiesis o autopoye-

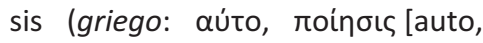
poiesis], 'a si mismo; creación, producción') es un neologismo propuesto en 1971 por los biólogos chilenos Humberto Maturana y Francisco Varela para designar la organización de los sistemas vivos. Una descripción breve sería decir que la autopoiesis es la condición de existencia de los seres vivos en la continua producción de sí mismos. $^{48}$

Básicamente, la estructura de la vida comprende tres elementos sin los cuales no puede existir y desarrollarse la misma:

1. Un interior caórdico ${ }^{49}$ (complejo) conformada por "redes de producciones

\footnotetext{
${ }^{48}$ Según Maturana y Varela son autopoiéticos los sistemas que presentan una red de procesos $\mathrm{u}$ operaciones (que los definen como tales y lo hacen distinguibles de los demás sistemas), y que pueden crear o destruir elementos del mismo sistema, como respuesta a las perturbaciones del medio. Aunque el sistema cambie estructuralmente, dicha red permanece invariante durante toda su existencia, manteniendo la identidad de este. Los seres vivos son en particular sistemas autopoiéticos moleculares, y que están vivos sólo mientras están en autopoiésis. Wikipedia. Autopoiésis. Octubre 28, 2013. http://es.wikipedia.org/wiki/Autopoiesis.

${ }^{49}$ Caord: 1) cualquier organización, comunidad, sistema u organismo complejo ya sea físico, biológico o social, que sea auto-organizado, auto-gobernado, adaptivo, y no-linear, y cuyo comportamiento se funde de manera armoniosa con las características tanto del orden como del caos. 2) es también una entidad cuyo comportamiento exhibe formas y probabilidades observables ni gobernadas y explicables por las leyes que gobiernan o explican sus partes constituyentes.
}

Caórdico: 1) el comportamiento de cualquier organismo, organización o sistema auto- 
moleculares en las que las moléculas producidas generan con sus interacciones la misma red que las produce".$^{50}$ Es decir, los núcleos de las células y su material genético definen y transfieren la información que permite la autopoiésis del organismo;

2. Una membrana semi-permeable que separa el material orgánico interno (en su individualidad y con sus características particulares) del entorno;

3. Un entorno, el cual, en relación con la complejidad interna del ser vivo, se considera caótico. Sin entorno no puede existir vida, por lo que el entorno se convierte en parte integral para la subsistencia de los organismos vivos; asimismo, existen entornos apropiados para ciertos seres vivos, y otros menos apropiados, mientras que otros que llegan a ser completamente destructivos y pueden causar la muerte (o sea, la suspensión de las funciones vitales).

La autopoiesis presupone que el interior de un organismo es el que define cuáles son los elementos que podrán ingresar al organismo, y cuáles tendrán que ser expulsados. También implica que la decisión - consciente o inconsciente- de qué ingresa y qué sale, es tomada desde dentro, no desde fuera. Esta es la estructura básica de la vida. El ADN da las instrucciones que permite la formación de las diferentes células en imagen y semejanza de sí mismas, que incluye la formación de una membrana semi-permeable con sus carac-

gobernado que funde de manera armoniosa las características tanto del orden como del caos. 2) formado de manera que no es dominado ni por el caos ni el orden. 3) características de los principios organizativos fundamentales de la evolución y la naturaleza.

${ }^{50}$ Wikipedia. Humberto Maturana. Octubre 28, 2013.

http://es.wikipedia.org/wiki/Humberto_Maturan $a$ : Transformación en la convivencia. terísticas específicas para proteger el organismo.

\section{El interior caórdico - las estructu- ras biológicas complejas y la autopoiesis}

La estructura biológica de los seres vivos incrementa su complejidad desde los seres unicelulares - formados por moléculas con diversas funciones físico-químicas, hasta aquellos multicelulares autoconscientes - los seres humanos-, pasando por una series de otros organismos cuyas moléculas se agrupan en complejos multicelulares con funciones diferenciadas - como en las plantas-, hasta formar los órganos internos - con funciones específicas cada vez más complejas y especializadas-, hasta llegar al invento de la evolución que conocemos como "cerebro".

La complejidad de este órgano que paradójicamente y para los propósitos de las metodologías educativas no ha sido tomado en cuenta-, se incrementa de acuerdo con el estado evolutivo de cada especie.

El ser humano posee un "cerebro trino", cuyas estructuras neurológicas poseen un orden que incluye la funcionalidad de los cerebros de especies anteriores:

a) La formación reticular, o "cerebro reptiliano" (tallo cerebral, filogenéticamente la formación más antigua del cerebro); sus funciones son principalmente fisiológicas y es el área del cerebro responsable de mantener las funciones fisiobiológicas tales como la temperatura del cuerpo y los controles cardiovasculares, los controles somático-motrices, la filtración de estímulos para la discriminación de estímulos irrelevantes, la modulación del dolor, habituación a estímulos repetitivos; 
está compuesto por 100 redes neuronales pequeñas.

b) El sistema límbico, o "cerebro paleo-mamífero"; gestiona respuestas fisiológicas a los estímulos emocionales; su funciones son varias, entre ellas las emociones, el comportamiento, la motivación, memoria de largo plazo, y el olfato.

c) La corteza cerebral, o "el cerebro humano"; la corteza cerebral es responsable de los niveles más altos de pensamiento, lenguaje, consciencia humana (la autoconsciencia), el razonamiento y la capacidad de abstracción.

Lo interesante aquí es que, mientras que las áreas "antiguas" del cerebro se forman durante el período de gestación, la corteza cerebral aún no llega a madurar hasta pasada la primera década luego del nacimiento.

Esta es la razón para la existencia de un fenómeno que Jean Piaget ${ }^{51}$ llamó las "etapas de desarrollo", las cuales definen cuáles son las "edades sensitivas" para la satisfacción de necesidades reales sensorio-motrices y afectivas, así como cognitivas y sociales, de un ser humano.

Son justamente éstas etapas sensitivas del desarrollo humano -que dependen de la madurez neuro-fisiológica de cada organismo-, las que el sistema educativo no toma en cuenta, así como no toma en cuenta o respeta la estructura autopoiética -el hacerse a sí mismo-, que es parte integral de la vida.

Esencialmente, y de forma muy resumida, la estructura autopoética está diseñada de tal manera para que las decisiones de lo ingresa en el organismo, y lo que necesariamente debe quedar afuera (puesto que interferirá con su adecuado desarrollo), proviene del interior; es decir, desde la membrana semi-permeable hacia adentro.

En otras palabras, cualquier estímulo o substancia que atente contra la estructura interna, genéticamente definida, limitará o hasta evitará los potenciales humanos de crecimiento y desarrollo.

Para ello, y a través de la evolución, el organismo ha definido una serie de parámetros físico, químico y biológicos, que deben cumplirse por medio de la permeabilidad selectiva de la membrana que separa a los organismos vivos de su entorno. La sabiduría innata de todo organismo implica que puede reconocer lo que le hace daño (inclusive de forma inconsciente), y rechazarlo, no permitiendo su entrada al organismo.

La apertura a estímulos externos se regula desde dentro, siendo el estado de relajación el que más apertura y sensibilidad permite. Así, en situaciones de riesgo, peligro o agresión, el organismo se bloquea frente a los estímulos externos, inclusive generando químicos que se riegan por el cuerpo para atacar y prepararse contra las situaciones de peligro. Uno de los síntomas es una reducción en la sensibilidad, así como en la capacidad de asimilación, que son reemplazadas por estrategias de supervivencia con reacciones manejadas desde las estructuras cerebrales antiguas (el reticular y el límbico), y que implican procesos biológicos tales como la inyección de adrenalina y endorfinas en la sangre, cambios en la respiración y la presión arterial, reacciones emotivas fuertes, reducción en la capacidad de razonamiento, entre otras, y

\footnotetext{
${ }^{51}$ Wikipedia. Jean Piaget. Octubre 28, 2013.
} 
que han demostrado, evocativamente, ser necesarias para las situaciones de peligro.

La membrana semi-permeable de los seres humanos

Los parámetros de permeabilidad física, química y biológica que presenta la membrana semi-permeable en los seres humanos (que separa su interior caórdico del exterior proporcionalmente caótico), provienen, como ya se vio, del interior de cada organismo. Es la manera cómo cada organismo logra mantener una separación de todo aquello que pueda causarle daño o, inclusive, destruir su frágil equilibrio interior.

En el caso de los seres humanos, el ADN ha creado una membrana con rangos de "input físico" característicos de la especie humana, visibles en la siguiente tabla:

http://es.wikipedia.org/wiki/Jean_Piaget 


\begin{tabular}{|c|c|c|c|}
\hline Estímulo & Receptor & Sensación & Interpretación \\
\hline $\begin{array}{l}\text { Ondas E-m } \\
10-5 \text { to } \\
10-4 \mathrm{~cm}\end{array}$ & Fotoreceptor & Luz, color & $\begin{array}{c}\text { Todas la impresiones } \\
\text { visuales }\end{array}$ \\
\hline $\begin{array}{l}\text { Ondas E-m } \\
10-4 \text { to } \\
10-2 \mathrm{~cm}\end{array}$ & $\begin{array}{c}\text { Piel } \\
\text { Termo-receptores }\end{array}$ & $\begin{array}{l}\text { Temperatura, } \\
\text { Caliente y frío }\end{array}$ & $\begin{array}{l}\text { Calor, fuego, confort, } \\
\text { congelamiento. }\end{array}$ \\
\hline $\begin{array}{c}\text { Oscilaciones mecánicas } \\
20 \text { a } 20.000 \mathrm{~Hz}\end{array}$ & Oído interno, cochlea & Ruidos, sonido & $\begin{array}{l}\text { sonidos, voces, tonos } \\
\text { musicales }\end{array}$ \\
\hline $\begin{array}{c}\text { Presión (14.7 a } 7.5 \text { psi } \\
\text { presión atmosférica re- } \\
\text { lativa) }\end{array}$ & $\begin{array}{c}\text { Tango-receptores de } \\
\text { la piel y preso- } \\
\text { receptores en el } \\
\text { cuerpo }\end{array}$ & $\begin{array}{l}\text { Tacto, peso, } \\
\text { aceleración, } \\
\text { deceleración }\end{array}$ & $\begin{array}{l}\text { Objetos, líquidos, esta- } \\
\text { dos de movimiento. }\end{array}$ \\
\hline Aceleraciones lineares & Otoliths & $\begin{array}{l}\text { Cambios, estado de } \\
\text { movimiento, equi- } \\
\text { librio }\end{array}$ & $\begin{array}{l}\text { Movimientos, movi- } \\
\text { mientos voluntarios e } \\
\text { involuntarios. }\end{array}$ \\
\hline Aceleraciones angulares & Canales semicirculares & Rotación & $\begin{array}{l}\text { Girar, rotaciones vo- } \\
\text { luntarias e } \\
\text { Involuntarias. }\end{array}$ \\
\hline $\begin{array}{l}\text { Químicos en solución } \\
\text { acuosa }\end{array}$ & Papilas del gusto & $\begin{array}{l}\text { Dulce, amargo, } \\
\text { agrio, salado }\end{array}$ & $\begin{array}{c}\text { Hambre, sed, procesos } \\
\text { digestivos }\end{array}$ \\
\hline $\begin{array}{l}\text { Químicos en estado ga- } \\
\text { seoso }\end{array}$ & Células del olfato & Olores & $\begin{array}{l}\text { Olores de ciertas } \\
\text { substancias }\end{array}$ \\
\hline $\begin{array}{l}\text { Cambios químicos y me- } \\
\text { cánicos internos }\end{array}$ & $\begin{array}{l}\text { Proprioceptores de los } \\
\text { músculos y tejidos que } \\
\text { los conectan }\end{array}$ & $\begin{array}{l}\text { Tensión y presión } \\
\text { interna }\end{array}$ & $\begin{array}{l}\text { Sentido de la posición } \\
\text { de los músculos y su } \\
\text { posición relativa con } \\
\text { las áreas contiguas }\end{array}$ \\
\hline $\begin{array}{c}\text { Zona de peligro: Efectos } \\
\text { de alta energía de toda } \\
\text { índole. }\end{array}$ & $\begin{array}{l}\text { Terminales nerviosas } \\
\text { de los órganos del } \\
\text { sentido }\end{array}$ & Dolor & $\begin{array}{l}\text { Estrés extremo, heri- } \\
\text { das, enfermedad. }\end{array}$ \\
\hline
\end{tabular}

Como es de esperarse, todo estímulo físico, químico o biológico que esté fuera del rango de permeabilidad, no podrá penetrar la membrana, o causará daños tanto a la membrana como a los tejidos internos, algunos de ellos irremediables.

Sin embargo, cuando ciertas substancias o elementos logran penetrar a pesar de la permeabilidad, éstas tendrán que ser expulsadas inmediatamente que des- truyan las células, los tejidos, o inclusive los órganos, a corto, mediano, o largo plazo. En casos en que esto no es posible, el sistema biológico tiene ciertas estrategias para aislar los compuestos tóxicos y expulsarlos, pero en otros, la acumulación de ciertos compuestos tóxicos pueden llegar a saturar el sistema y enfermarlo. ${ }^{52}$

\footnotetext{
52 Acumulaciones de plomo, de arsénico, de organo-clorados o inclusive partículas radiactivas, son un ejemplo de esto.
} 
La membrana también está diseñada para permitir la salida y expulsión de aquellas substancias que no le son necesarias, o que podrían llegar a ser tóxicas, o que se convierten en los restos de los procesos biológicos de asimilación, como son la expulsión de dióxido de carbono luego del proceso de respiración, la eliminación de toxinas por medio de la piel (en el peor caso, por medio de superaciones), y la eliminación de excrementos y orina, inclusive vómito. Si estas necesidades biológicas son postergadas, causan un estado de estrés que, con el tiempo, pueden causar problemas de salud.

Si bien desde el punto de vista fisiobiológico se tiene en claro cuáles son los parámetros considerados como saludables, cuando entramos en el área cognitiva, su incursión y asimilación no son tan claras, y por lo tanto no son muy tomadas en cuenta cuando se trata de "educar" a los seres humanos, confundiéndose muchas veces la capacidad de "memorización" desde edades tempranas, con una apropiada "asimilación". Por un lado, esta capacidad de asimilación depende de la edad, y por otro, de la manera cómo los "materiales culturales" entran en el ser humano.

\section{Las etapas del desarrollo}

Para Jean Piaget ${ }^{53}$ (1896-1980), psicólogo del desarrollo ${ }^{54}$ (también conoci-

\footnotetext{
${ }^{53}$ Wikipedia. Jean Piaget. Octubre 28, 2013. http://en.wikipedia.org/wiki/Jean_Piaget / http://es.wikipedia.org/wiki/Jean_Piaget /

${ }^{54}$ Wikipedia. Developmental psychologist. Octubre 28, 2013.

http://en.wikipedia.org/wiki/Developmental_psy chologist / Wikipedia. Psicología del desarro-

llo. Octubre 28, 2013.

http://es.wikipedia.org/wiki/Psicolog\%C3\%ADa _del_desarrollo
}

da como la psicología evolutiva ${ }^{55}$ ), la inteligencia humana es parte de un proceso biológico ${ }^{56}$ con una herencia evolutiva. Debido a que el cerebro (y todo el organismo humano) aún está en estado de desarrollo cuando nace, sus estructuras internas cambian, siendo estas influenciadas por el entorno por medio de un proceso de adaptación.

Esta adaptación pasa por "etapas sensitivas del desarrollo" ${ }^{17}$ donde las células y las estructuras biológicas internas tienen "períodos críticos", o "estadios" los cuales son como un despertar del potencial de nuevas habilidades.

Piaget descartó la idea de que la evaluación del pensamiento $y$ el desarrollo cognoscitivo fuese un proceso continuo o simplemente lineal, describiendo en cambio períodos o estadios en los que se configuran determinados esquemas característicos y en los que se generan las condiciones para que se produzca el salto al próximo estadio, caracterizado de una nueva manera y por nuevos esquemas. En algunos estadios prevalece la «asimilación», en otros la "acomodación». Definió esencialmente una secuencia de cuatro grandes estadios o períodos, que su vez se

\footnotetext{
${ }^{55}$ Wikipedia. Psicología evolutiva. Octubre 28, 2013.

http://es.wikipedia.org/wiki/Psicolog $\% C 3 \% A D a$ evolutiva

${ }_{56}$ Psichopedagogía.com. Teoría de Piaget. Octubre 28, 2013.

http://www.psicopedagogia.com/articulos/?arti culo $=379$

${ }^{57}$ UNID, Materia en línea, Maestría en Educación. Los cuatro períodos de desarrollo de Piaget.

http://moodle.unid.edu.mx/dts_cursos_mdl/maes tria_en_educacion/teo_aprendiz_instruc/docum entos/DesarrolloPiaget $2 . p d f$
} 
dividen en subestadios. Los estadios se suceden, de acuerdo a la «epistemología genética» piagetana de modo tal que en cada uno de ellos se generan (a eso se refiere aquí el término "genético») las condiciones cognoscitivas a nivel del pensamiento para que pueda aparecer el estadio siguiente ${ }^{58}$.

Los descubrimientos neurológicos posteriores a la creación de su Teoría Constructivista del Aprendizaje han logrado, en gran medida, confirmar la validez ${ }^{59}$ de lo propuesto por Jean Piaget, si bien sus observaciones no continuaron más allá del período de la pubertad.

En situaciones de ambientes norelajados, por ejemplo, ha sido más difícil percibir los estadios de las etapas sensitivas del desarrollo, ${ }^{60}$ ya que las condiciones a las cuales han estado expuestos los niños han provenido de expectativas exteriores a su organismo, y no a su "plan interno" de desarrollo.

En aquellos espacios donde se ha respetado la condición autopoiética de los niños y los jóvenes, ${ }^{61}$ las etapas de desarrollo han sido mucho más visibles y coherentes con lo presentado por Jean Piaget, sin

\footnotetext{
${ }^{58}$ Wikipedia. Jean Piaget. Octubre 28, 2013. http://es.wikipedia.org/wiki/Jean_Piaget 59 Jean Piaget Society. Developmental Social Cognitive Neuroscience. Octubre 28, 2013. http://www.piaget.org/Symposium/2007/. ${ }^{60}$ Zelazo, Philip David, Chandler, Michael, Denver, John, Crone, Evelyn, Editores. (Agosto 28, 2012). Developmental Social Cognitive Neuroscience. Londres: Psicology Press Ltd. Fishpond.com.au.

http://www.fishpond.com.au/Books/Developmen tal-Social-Cognitive-Neuroscience-PhilipDavid-Zelazo-Edited-by-Michael-ChandlerEdited-by/9780415647212.

${ }^{61}$ Wild, Rebeca. (2011). Etapas de desarrollo. Barcelona: Herder.
}

menospreciar el hecho de que muchas de sus observaciones no incluían ciertas influencias sociales, tales como el rol de los adultos en el ambiente, y las relaciones con otros niños. ${ }^{62}$

Más allá de la polémica de cuán certero fue Piaget en presentar sus etapas de desarrollo, y cuán expansivas fueron sus investigaciones para incluir elementos del entorno social y cultural, el hecho es que si el ambiente carece de aquellos elementos necesarios para desarrollar los potenciales humanos presentes en su genética, estos no lograrán activarse por completo, quedando truncados en su desarrollo. A breves rasgos, las etapas de desarrollo son: ${ }^{63}$

1) El período sensorio-motriz - de 0 a 3 años de edad; ${ }^{64}$

2) El período pre-operacional - de los 3 hasta los 7/8 años de edad; ${ }^{65}$

3) El período de las operaciones concretas - de los 7/8 hasta los 13/14 años de edad; ${ }^{66}$

4) El período de las operaciones formales - de 13 a los 24 años en adelante. ${ }^{67}$

62

http://thebrain.mcgill.calflash/i/i_09/i_09_p/i_0 $9 \_p \_d e v / i \_09$ p_dev.html / Wild, Rebeca. Etapas de desarrollo.

${ }^{63}$ Wild, Rebeca. Etapas de desarrollo. Por más de 30 años, la Fundación Educativa Pestalozzi funcionó en Tumbaco, Ecuador, y miles de niños pasaron por sus ambientes preparados. En ningún otro lugar se hicieron observaciones y anotaciones tan exhaustivas como durante el tiempo que funcionó este plantel educativo. Las edades aquí presentadas han sido producto de observaciones hechas durante los 30 años de existencia de la institución educativa.

${ }^{64}$ Jean Piaget proponía de 0 a 2 años de edad. Wild, Rebeca. Etapas de desarrollo. pp. 29-41. ${ }^{65}$ Jean Piaget proponía de 3 a 7 años de edad. Wild, Rebeca. Etapas de desarrollo. pp. 43-54. ${ }^{66}$ Jean Piaget proponía de 7 a los 12 años de edad. Wild, Rebeca. Etapas de desarrollo. pp. 55-72. 
5) La etapa de desarrollo de los adultos - de 24 años en adelante. ${ }^{68}$

Debe considerarse también que cada período o etapa sensitiva del desarrollo se superpone, y que su proceso de asimilación y acomodación no es linear. Igualmente, y como se lo mencionó con anterioridad, cuando el organismo ha estado expuesto a un ambiente no-relajado, sus períodos sensitivos no pueden expresarse o activarse por completo, porque el organismo se encuentra en un estado de insensibilidad crónica provocada por las "estrategias de supervivencia" que justamente reducen las capacidades cognitivas y de apertura al entorno.

\section{Ambientes apropiados para la subsistencia y el desarrollo humano}

Si bien el ser humano es sumamente adaptable y capaz de sobrevivir en ambientes extremos (desde los fríos siberianos hasta los calores africanos), en términos generales, el organismo humano requiere de ciertos parámetros preestablecidos que se consideran como sanos u óptimos para su subsistencia.

Desde el punto de vista físico, los rangos de temperatura, radiación (visible y no visible), niveles de ruido así como la cantidad y calidad de los gases a los que se expone, han sido estudiados con bastante prolijidad. Nadie discute que ciertos rangos de estímulos, al ser sobrepasados, no solo que son perniciosos, sino que pueden cau-

\footnotetext{
${ }^{67}$ Jean Piaget proponía de los 12 años de edad en adelante, siendo esta una de las críticas que se han hecho a su teoría, puesto que no consideraba desarrollos posteriores considerables en la etapa de las operaciones formales. Wild, Rebeca. Etapas de desarrollo. pp. 73-84.

${ }^{68}$ Wild, Rebeca. Etapas de desarrollo. pp. 85119.
}

sar la muerte. En otras palabras, el entorno físico que nos rodea juega un rol importante en nuestro estado de salud y crecimiento.

Desde el punto de vista químico, ocurre algo parecido. Existen substancias que simplemente son perjudiciales, ya sea por su contacto con nuestra membrana semi-permeable, o por su ingestión. Estudios sobre la alimentación demuestran que ciertos alimentos son estrictamente necesarios para mantener la salud humana, sin los cuales, a corto, mediano, o a largo plazo, acabaremos enfermos o pereceremos. Tanto la desnutrición como la sobrealimentación son malos. En todo momento, no obstante, es el organismo el que decide -luego de que los alimentos hayan entrado por la membrana semipermeable-, cuáles son los elementos que requerirá para que el cuerpo encuentre su equilibrio, cuáles son asimilados, y cuáles serán expulsados. A menos que suframos de ciertos problemas sicológicos o emocionales, o que vivamos una vida desequilibrada en cualquier sentido, el cuerpo logra mantenerse en buen estado de salud sin mayor problema. Pero cuando el ambiente -que incluye la cultura a la que estamos expuestos-nos expone a prácticas malsanas, no durará mucho antes que nuestro cuerpo físico entre en desequilibrios.

El nivel biológico incluye los parámetros impuestos por los rangos físicos y químicos, con la complejidad agregada de que, además de los estímulos sensoriomotrices, existe niveles afectivos, emocionales, y cognitivos. Estos se encuentran conformados por el entorno socio-cultural.

Así como el ser humano no puede sobrevivir sin alimento, en ciertas etapas tempranas de la vida no puede existir sin 
contacto físico con otros seres humanos. Inclusive más tareas, la carencia de contacto físico y relaciones sociales apropiadas pueden causar estragos no solo emocionales y psicológicos, sino inclusive fisiológicos (psicosomáticos) que, a su vez, generarán problemas en los procesos biológicos a nivel molecular, celular, y orgánico.

Es decir, si las necesidades reales del ser humano no son correspondidas y satisfechas, nuestro organismo comenzará a mostrar deficiencias tanto neurológicas, como biológicas, inclusive químicas y físicas. No obstante, ¿se pregunta la educación -y quienes están a cargo de crear los currículos de aprendizaje cognitivo-, cuáles son estas necesidades reales que deben ser satisfechas para que los seres humanos puedan llegar a cumplir con su pleno potencial presente en el ADN?

La respuesta a esta pregunta es: No.

No, los currículos no contemplan las necesidades reales de desarrollo humano de acuerdo a cómo funciona la estructura de los procesos de vida y su autopoiésis. Los currículos contienen "el conocimiento" y "las creencias vigentes" de cómo funciona el mundo, y están definidos por las metas que se quieren conseguir, $y$ que se creen necesarias para el desarrollo de la sociedad (de acuerdo a la filosofía y a las políticas de un gobierno así como del gremio académico).

Los currículos, por cierto, varían de acuerdo a los posiciones sociales, religiosas y políticas de los estados, inclusive de los mismos educadores, presentando lo que se cree es necesario que los ciudadanos aprendan para lograr integrarse a la sociedad y cumplir con las expectativas, los in- tereses, y los ideales político-económicos del paradigma oficial vigente. En ningún momento existe un conocimiento y comprensión cabal de lo que un niño realmente necesita para desarrollarse como un ser humano que ha sido respetado de acuerdo a su "programa interno". No obstante, nuestra adaptabilidad permite, hasta cierto punto, esconder los desequilibrios inherentes en el "mal trato" del organismo humano, y como estos desequilibrios han sido tan generalizados, es difícil reconocer los síntomas de una enfermedad socioeducativa que podría llamarse "Síndrome de Educación Deficiente Adquirida".

En términos generales, en la actualidad no existe un entorno educativo apropiado para que el potencial humano consiga expresarse en su totalidad. Al contrario. La "riqueza" de los entornos donde pasan la mayoría de los seres humanos durante más de una década, deja mucho que desear. Ya desde el hogar existe un desconocimiento crónico de lo que realmente requerimos los humanos para desarrollarnos de acuerdo a nuestro potencial interno. Este potencial se ve aún más reducido al entrar en las aulas de clases donde nuestras necesidades sensorio-motrices y afectivas se ven aún más coartadas. Ciertos comportamientos considerados apropiados, como una obediencia ciega, o mantenerse en silencio, por ejemplo, van contra las necesidades fisiológicas de hacer movimientos físico regulares, o de ejercitar la motricidad fina en coordinación con los sentidos del tacto, olfato, auditivo, gustativo, truncando así aspectos importantes -e indispensables - del crecimiento y desarrollo humano.

María Montessori descubrió la posibilidad de crear materiales didácticos que, al utilizarse, ejercitan lo sensorio- 
motriz. Dependiendo de la edad (Piaget diría la etapa sensitiva de desarrollo), las necesidades sensorio-motrices van de lo grueso a lo fino, por lo que el entorno debería tener materiales adecuados para satisfacerlas. Así, por ejemplo, en vez de un sistema decimal abstracto (números escritos en papel), los más pequeños aprenden tocando, jugando y manipulando objetos físicos, que van desde lo más concretopalos, bloques o mullos que representan unidades - hacia lo más abstracto- mullos que representan valores de acuerdo a su color. La riqueza del material concreto no se limita a lo numérico solamente, o sea, a lo cuantitativo, sino también a lo cualitativo. Así, tanto el tacto como el olfato, el gusto y la vista, cuentan con una serie de materiales didácticos los cuales, al ser manipulados, permiten descubrir aspecto del entorno los cuales, con la repetición, llegan a ser asimilados, permitiendo así la creación de estructuras neurológicas internas. Si esto ocurre de manera relaja$\mathrm{da}$, en ambientes preparados carentes de peligros y presiones, el proceso de asimilación y aprendizaje es mucho más completo y duradero, que si los niños y jóvenes están en un entorno de tensión, donde las decisiones de qué deben hacer, y cómo, provienen de fuera (en contra de las estructuras de autopoiesis).

\section{La creación en masa de bonsáis} humanos

Los bonsáis son árboles en miniatura, originalmente una práctica China, que luego fue aprendida por los japoneses.

Bonsái (곅草?) es una palabra de origen japonés que significa literalmente bon = 'bandeja' + sai = 'naturaleza' (aunque etimológicamente procede del término chino $A$ 駛, penzai, que significa pén = 'bandeja' + zāi = 'cultivar') y consiste en el arte de cultivar árboles y plantas, reduciendo su tamaño mediante técnicas, como el trasplante, la poda, el alambrado, el pinzado, etc., y modelando su forma para crear un estilo que nos recuerde una escena de la naturaleza $(. .$.

El arte del bonsái se originó en China hace unos dos mil años, como objeto de culto para los monjes taoístas. Para ellos era símbolo de eternidad, el árbol representaba un puente entre lo divino y lo humano, el cielo y la tie$\mathrm{rra}^{69}$

Existen clasificaciones por estilos de bonsái, así como por tamaños, pero todos tienen algo en común: la poda sistemática de sus brotes, ramas, y hojas, o hasta partes del tronco, para crear un árbol en miniatura.

Dependiendo del estilo deseado, inclusive se colocan cartones o cintas para que las ramas que queden, crezcan en la dirección deseada en busca de la luz (procurando disimular las cicatrices). También se pueden desenraizar los árboles jóvenes, quitándoles la mayoría de la tierra, para luego colocarlos sobre rocas o piedras de manera que las raíces se fijen en ellas.

Si bien un bonsái logra vivir lo mismo que un árbol común, jamás podrá llegar a ser un árbol de acuerdo a su potencial genético. Los bonsáis son, por definición, árboles truncados en su crecimien-

${ }^{69}$ Wikipedia. Bonsái. Octubre 28, 2013. http://es.wikipedia.org/wiki/Bons\%C3\%Ali 
to, que han sido limitados a vivir en bandejas o en macetas, y donde literalmente un abuso controlado por medio de mutilaciones recurrentes los convierte en árboles enanos.

Con el advenimiento de la Era de la Información con sus sistemas de comunicación globalizados y procesamiento de datos medidos en nano-segundos, así como en las capacidades de acumulación de información en terabytes, petabytes, exabytes y zettabytes, creemos que "al conocer", comprendemos. Sin embargo, al no tomar en cuenta cómo funcionan los procesos de aprendizaje dentro del cerebro, perdemos una gran oportunidad, inclusive producimos un efecto similar, desde el punto de vista neurofisiológico y cognitivo, del que se ve en la creación de bonsáis.

La restricción sistemática de la iniciativa y a la capacidad de creatividad y razonamiento, las restricciones físicas, emocionales y psíquicas en ambientes norelajados (que poseen además escasos elementos de interacción sensorio-motriz y afectiva), ya son suficientes para truncar el crecimiento de los educandos. Al sumarse a esto los condicionamientos diarios $\mathrm{y}$ permanentes - por medio de castigos por desobediencia, por impuntualidad, por "mal-comportamiento" así como por falta de "rendimiento académico"-, se evita la satisfacción de las necesidades reales presentadas en cada una de las etapas sensitivas del desarrollo, lo que da como resultado seres humanos formados de acuerdo a un currículo que ignora los verdaderos potenciales de cada individuo ( $y$ de la especie humana), forzándolos a ajustarse a las expectativas socio-políticas y económicas vigentes.
Cuando los resultados de la educación formal no son los esperados, incrementamos la presión sobre los educandos -y los educadores - para conseguir un mayor control de los contenidos y de los "resultados", sin darnos cuenta que con esto estamos actuando contra natura.

El concepto de aprendizaje como una imposición de contenidos socioculturales que se introducen en un organismo humano desde fuera, y luego, para comprobarse el "nivel de captación", se utiliza una metodología para atestiguar o demostrar que los contenidos han sido "asimilados", ignora por completo el verdadero proceso de asimilación neurobiológica.

Cuando asimilamos una manzana, no esperamos que la manzana sea devuelta entera luego de que sacamos provecho de ella. Los procesos de asimilación cognitiva funcionan de manera similar. La devolución de la información adquirida por medio de exámenes, en función de expectativas externas de que los resultados deben ser los mismos que la información y los conocimientos impartidos, no desemboca en una comprensión de los contenidos, sino en una repetición programada y condicionada.

Si vemos lo que ocurre realmente en un aula, y nos preguntamos cuál es el proceso integral al cual nos exponemos cuando nos "educamos", veremos varios fenómenos.

Desde el punto de vista físico, los ambientes están comúnmente preparados para que los alumnos se sienten para escuchar y ver en una misma dirección. Y estos ambientes no son ricos en estímulos sensorio-motrices (ni afectivos), sino más bien 
lo contrario, son un desierto sensorial y motriz y, en la mayoría de los casos, la "afectividad" es completamente impersonal. Así como a un bonsái se le cortan las raíces y las guías para "formarlo" de acuerdo a las expectativas o deseos de quién lo crea, se coartan las necesidades fisiológicas de los educandos, ignorándose por completo sus etapas de desarrollo y potenciales genéticos.

Desde el punto de vista cognitivo, la manera como se pretende que ocurra la aprehensión de conocimientos, es igualmente irrespetuosa de las necesidades reales. No solo se basan los currículos en la acumulación progresiva de información y conocimiento (principalmente por vías de la memorización), sino que, además, provienen de una relación donde el educando debe obedecer y acatar las doctrinas, no solo de contenidos, sino de comportamientos que lo llevan a la sumisión y a la subordinación repetida y recurrente, la cual acaba condicionando al individuo.

Algo similar ocurre con el sentimiento y la certeza de que todas las preguntas ya tienen respuesta, con lo cual se logra coartar la curiosidad y la creatividad de forma sistemática. La adquisición de conocimientos se convierte en una relación donde ya sea se premia - o castiga - la "falta de atención" y la no conformación con las órdenes dadas.

Estos son procesos de vida que forman a los individuos de acuerdo a las expectativas culturales y sociales, inclusive económicas, que muy poco o nada tienen que ver con el verdadero potencial que tiene el ser humano para desarrollarse. 